\title{
Effectiveness of a community-based diabetes self-management education (DSME) program in a rural agricultural setting
}

\author{
Elizabeth Paz-Pacheco ${ }^{1}$, Mark Anthony Sandoval ${ }^{1}$, Gregory J. R. Ardena ${ }^{1}$, Elizabeth Paterno ${ }^{2}$, Noel Juban ${ }^{3}$ \\ Frances L. Lantion-Ang ${ }^{1}$, Cecilia Jimeno ${ }^{1}$, Perpetua Patal ${ }^{1}$ and Joseph Bongon ${ }^{1}$ \\ ${ }^{1}$ Section of Endocrinology, Diabetes and Metabolism, Department of Medicine, College of Medicine and Philippine \\ General Hospital, University of the Philippines Manila, Manila, Philippines \\ ${ }^{2}$ Community Health and Development Program, University of the Philippines Manila, Manila, Philippines \\ ${ }^{3}$ Department of Clinical Epidemiology, College of Medicine, University of the Philippines Manila, Manila, Philippines
}

\begin{abstract}
Introduction: The purpose of this study is to assess the effectiveness of diabetes self-management education (DSME) in a rural agricultural town. Methods: In this prospective, education-intervention trial, 85 adults with type 2 diabetes mellitus from villages randomly assigned to DSME and 70 from villages assigned to standard care participated. The DSME group underwent a curriculum delivered by peer educators; those in the standard group received usual advice. Outcome measures were anthropometric, biochemical, health behaviors, and medication use data taken at baseline then after three and six months. Results: DSME group had a lower median A1C after three and six months. After six months, there was a $0.5 \%$ median $\mathrm{A} 1 \mathrm{C}$ reduction in DSME group and a $0.25 \%$ increase in the standard group. There were more participants in DSME group with $\mathrm{A} 1 \mathrm{C} \leqslant 7.0 \%$ after three and six months. By the third month, there were more participants in DSME group performing foot examination. Conclusion: DSME in this rural agricultural town improved glycemic control and promoted foot examination.
\end{abstract}

Key words: community medicine; diabetes mellitus; health education; rural health; rural population

Received 30 September 2015; revised 5 August 2016; accepted 21 August 2016; first published online 19 September 2016

\section{Introduction}

The Philippine National Nutrition and Health Survey II in 2008 revealed a national diabetes prevalence of $7.1 \%$, with a prevalence of $8.3 \%$ in

\footnotetext{
Correspondence to: Dr. Mark Anthony Sandoval, Section of Endocrinology, Diabetes and Metabolism, Medical Research Laboratory, 2nd floor, Philippine General Hospital, Taft Avenue, Manila 1000, Philippines. Email: markanthony_ sandoval@yahoo.com

Presented as Oral Presentation, World Diabetes Congress 2011, Dubai, United Arab Emirates, Presented as Oral Presentation, Philippine Research Initiatives in Diabetes and Endocrinology (PRIDE), Philippine Society of Endocrinology and Metabolism Annual Convention 2012, Presented as a Poster, World Diabetes Congress 2013, Melbourne, Australia.
}

(C) Cambridge University Press 2016 urban areas and $5.8 \%$ for rural areas (Sy et al., 2012).

Diabetes self-management education (DSME) is one intervention aimed at improving the provision of care and achieving better metabolic control for patients with diabetes. It is an interactive, collaborative, ongoing process involving the person with diabetes and the educator (Mensing et al., 2000).

A review of randomized clinical trials revealed conflicting conclusions on the effectiveness of this educational strategy (Norris et al., 2001). There were improvements in dietary habits, knowledge levels, and self-monitoring of blood glucose in follow-ups less than six months. This translates to a reduction in A $1 \mathrm{C}$ by $0.7 \%$ on immediate follow-up with a further decrease of $1 \%$ noted for every additional $24 \mathrm{~h}$ of 
contact (Norris et al., 2002). On the other hand, some studies showed that improvements in glycemic control do not necessarily translate to measured changes in knowledge or DSME skills. Moreover, there was an inverse relationship between follow-up time and improvements on glycemic control and behavioral outcomes, questioning the sustainability of this intervention (Norris et al., 2001).

Establishing a community-based diabetes selfmanagement program poses myriad challenges and considerations. The rural community is characterized by low-income populations with lower education levels, fewer providers serving a high volume of patients, and limited resources for adequate diabetes management (Fraser et al., 2006). Perceiving these characteristics as challenges rather than limitations, our group embarked on a program to assist in the provision of effective measures in the surveillance and control of diabetes.

\section{Objective}

To assess the effectiveness of a community-based DSME program in improving anthropometric, biochemical, and health behavior outcomes among persons with diabetes.

\section{Methodology}

\section{Program setting}

The municipality of San Juan in the province of Batangas in the Philippines was the setting of this study. It is a rural agricultural town $120 \mathrm{~km}$ south of Manila. It has one municipal health officer, three rural health physicians, and nine municipal public health nurses serving a population of around 80000 people.

\section{Program participants}

Of the 42 villages or barangays, 19 were selected from which participants were recruited. Instead of the individual participants being randomized, it is the villages where they reside which were randomized to receive either the DSME program or standard care. There were nine villages assigned to receive the DSME program, whereas 10 villages received standard care.

Participants were recruited by announcement by village health workers (for those already known to have diabetes) or after they have been

Primary Health Care Research \& Development 2017; 18: 35-49 newly identified to have diabetes in the earlier prevalence study that our group has conducted (Sandoval et al., 2016).

Each participant was asked to give an informed consent and underwent an interview, physical examination and blood extraction by our team of endocrinologists. The following data were collected: (1) socio-demographic: age, sex, religion, educational attainment; (2) medical history: type of diabetes, duration of diabetes, presence of diabetes complications, medications being taken, other illnesses; (3) anthropometric: height, weight, body mass index (BMI), waist circumference, hip circumference, waist-hip ratio (WHR), blood pressure; (4) biochemical: A1C, fasting blood glucose (FBG), total cholesterol, low density lipoprotein (LDL), high density lipoprotein (HDL), and triglycerides; and (5) health behavior: smoking, alcohol consumption, illicit drug use, exercise, and foot examination. Biochemical tests were performed in the same laboratory throughout the entire duration of the study.

To achieve an $80 \%$ power to detect a $0.9 \%$ absolute difference in the A1C between groups, the computed sample size is at least 64 per group (Kronsbein et al., 1988).

\section{DSME}

\section{Peer educators}

In total, 14 volunteer peer educators were recruited among the participants. There was no educational attainment or profession that was required of the peer educators; only the willingness to be trained and eventually share the knowledge to others. Among the peer educators were a village leader (barangay chairman), a retired school principal, a village health worker, a village nutrition scholar, a jeepney driver, whereas the rest were housewives. They attended a two-day workshop during which they received a course manual that described both the course content and process on how to teach them. Endocrinologists from our group conducted the workshop. After the peer educators were trained, they were asked to do a return demonstration.

This strategy focuses on training lay health advisors, who will function as 'community catalysts,' to promote a healthy lifestyle among people with diabetes in the community (Plescia and Groblewski, 2004). Based on previous studies, 
successful diabetes programs in rural communities tend to have committed, dedicated leaders with the vision of providing holistic, quality health care relevant to the rural environment (Salman, 2005).

\section{Program content}

Participants in both groups were given oral advice on diet, exercise, foot care, and medication compliance on each follow-up visit. The participants in the intervention group additionally received DSME as described here.

Modules developed by the International Diabetes Federation (IDF) Consultative Section on Diabetes Education (DECS) in 2002 were translated into Filipino by the Sentro ng Wikang Filipino (Center of the Philippine Language) of our university. The translated modules were modified according to the participants' level of knowledge.

There were eight modules in the DSME program: (1) overview of diabetes mellitus, (2) diabetes and exercise, (3) diabetes and diet, (4) pharmacologic treatment of diabetes, (5) insulin use, (6) acute complications of diabetes, (7) microvascular and macrovascular complications of diabetes, and (8) foot care.

These modules were delivered by peer educators with visual aids followed by group discussions. The teaching sessions were held in the village health centers, with six to 15 participants in attendance in each session. Local venues are good settings for DSME interventions because the educator can address issues that can be more difficult to deal with in the clinical setting, such as cultural, family, and environmental factors affecting lifestyle and barriers to optimal self-care (Task Force on Community Preventive Services, 2002). Two modules were taught per session. Each of the four weekly sessions lasted for $\sim 1 \mathrm{~h}$.

\section{Follow-up visits and outcome measures}

Data taken at baseline were again determined after three and six months.

The outcome measures in both groups were analyzed in terms of differences in (1) mean or median values, (2) change from baseline, and (3) the proportion of participants achieving the recommended anthropometric and biochemical measures for persons with diabetes.
The recommended values are as follows: BMI $\leqslant 22.9 \mathrm{~kg} / \mathrm{m}^{2}$; waist circumference (males) $\leqslant 90 \mathrm{~cm}$, (females) $\leqslant 80 \mathrm{~cm} ;$ WHR (males) $\leqslant 1.0$, (females) $\leqslant 0.9$; blood pressure $\leqslant 130 \mathrm{mmHg}$ systolic and $\leqslant 80 \mathrm{mmHg}$ diastolic; A1C $\leqslant 7.0 \% ; \mathrm{FBG} \leqslant 130 \mathrm{mg} / \mathrm{dL}$ $(\leqslant 7.2 \mathrm{mmol} / \mathrm{L}) ;$ total cholesterol $\leqslant 200 \mathrm{mg} / \mathrm{dL}$ $(\leqslant 5.18 \mathrm{mmol} / \mathrm{L}) ; \mathrm{LDL} \leqslant 100 \mathrm{mg} / \mathrm{dL}(\leqslant 2.6 \mathrm{mmol} / \mathrm{L})$; HDL (males) $\geqslant 40 \mathrm{mg} / \mathrm{dL}(\geqslant 1.04 \mathrm{mmol} / \mathrm{L})$, (females) $\geqslant 50 \mathrm{mg} / \mathrm{dL} \quad(\geqslant 1.30 \mathrm{mmol} / \mathrm{L}) ;$ and triglycerides $\leqslant 150 \mathrm{mg} / \mathrm{dL}(\leqslant 1.70 \mathrm{mmol} / \mathrm{L})$.

Results of the physical examination and laboratory testing were fed back to the participants of both groups at each time point. Lifestyle interventions were emphasized for any abnormal result. Medications for hyperglycemia, hypertension, and dyslipidemia were prescribed, if needed, but were not provided by the investigators. Participants were encouraged to follow-up with their personal physicians if they have one. Those without a personal private physician were referred to the municipal health office after the study for continuity of diabetes care.

\section{Statistical analysis}

The data from the DSME and standard care groups were compared at baseline and after three and six months.

A two-by-two contingency table was used to present the descriptive statistics at baseline, three and six months. The mean $( \pm \mathrm{SD})$, median [interquartile range (IQR)] and count (\%) were computed for normal, non-normal, and categorical data sets, respectively. Shapiro-Wilk's test was employed to test the normality of the data.

Independent samples $t$-test and Mann-Whitney test were carried out to test for differences in means and medians, respectively, of the outcome measures expressed as continuous variables. $\chi^{2}$-test or Fisher's exact test, whichever was appropriate, was employed to test for differences in proportions for outcome measures expressed as categorical variables. The test is significant if $P$-value $<0.05$. Data were encoded and analyzed using Stata IC 13.

\section{Ethics approval}

This study was given technical and ethical approval by the Research Implementation and Development Office of the College of Medicine of the University of the Philippines Manila.

Primary Health Care Research \& Development 2017; 18: 35-49 


\section{Results}

\section{Baseline characteristics}

There were 85 participants recruited from the villages randomized in the DSME group and 70 participants from the villages in the standard care group (total of 155 participants). Average age is 57.1 years, with majority of the participants being females $(70 \%)$. Majority $(80 \%)$ of the participants were married. In all, $26 \%$ had an educational attainment of under elementary (i.e., did not complete six years of basic education), $37 \%$ completed elementary level (i.e., completed six years of basic education), $24 \%$ reached high school, whereas only $13 \%$ reached college. Average duration of diabetes is 4.39 years. Participants in the two groups did not have significant differences in terms of the socio-demographic characteristics except that there were more widows/widowers in the standard care group than the DSME group (Table 1).

Likewise, there were no differences in the baseline anthropometric and biochemical characteristics (Tables 2 and 3). Among the behaviors, fewer participants in the DSME group performed regular exercise and foot examination (Table 4).

\section{Follow-up}

On the third month, there were 65 of 85 (76\%) in the DSME group who were able to follow-up, whereas there were 59 of $70(84 \%)$ in the standard care group. There was one participant in the
DSME group who died, hence, no follow-up on the third month.

On the sixth month, 72 of 85 participants (85\%) in the DSME group and 52 of 70 participants $(74 \%)$ in the standard group were able to followup. There was one more participant in the DSME group and one participant in the standard care group who died and therefore was not able to follow-up on the sixth month. All in all, there were two who died in the DSME group and one in the standard care group by the end of the six-month study period.

\section{Anthropometric measures (see Table 2)}

There were no significant differences in the mean BMI and diastolic blood pressure between the DSME and standard care group at all time points - that is, at baseline, on the third month and on sixth month. However, WHR for females was higher in the DSME group compared with the standard care group on the third month (median of 0.93 versus $0.88, P=0.02$ ). Likewise, mean systolic blood pressure was seen to be higher in the DSME group compared with the standard care group on the sixth month (median of 130 versus $120 \mathrm{mmHg}, P=0.02$ )

The proportions of participants achieving the recommended anthropometric measures for Asians were also analyzed at baseline, third and sixth month. The proportions of those who had appropriate weight $\left(\mathrm{BMI} \leqslant 22.9 \mathrm{~kg} / \mathrm{m}^{2}\right)$, were overweight (BMI $\left.23.0-24.9 \mathrm{~kg} / \mathrm{m}^{2}\right)$ and were obese

Table 1 Socio-demographic characteristics of the participants

\begin{tabular}{|c|c|c|c|c|}
\hline Characteristics & $\begin{array}{l}\text { All } \\
(n=155)\end{array}$ & $\begin{array}{l}\text { DSME } \\
\text { group }(n=85)\end{array}$ & $\begin{array}{l}\text { Standard care } \\
\text { group }(n=70)\end{array}$ & $\begin{array}{l}P \text {-value (DSME versus } \\
\text { standard care groups) }\end{array}$ \\
\hline Age in years [mean (SD)] & $57.1(11.5)$ & $57.6(11.5)$ & $56.5(11.7)$ & 0.56 \\
\hline Males $[\mathrm{n}(\%)]$ & $46(30 \%)$ & $25(29 \%)$ & $21(30 \%)$ & 0.94 \\
\hline Civil status & & & & 0.01 \\
\hline Single $[n(\%)]$ & $13(8 \%)$ & $7(8 \%)$ & $6(9 \%)$ & \\
\hline Married $[n(\%)]$ & $124(80 \%)$ & $74(87 \%)$ & $50(71 \%)$ & \\
\hline Widow $[n(\%)]$ & $19(12 \%)$ & $4(5 \%)$ & $14(20 \%)$ & \\
\hline Educational attainment & & & & 0.24 \\
\hline Under elementary $[n(\%)]$ & $40(26 \%)$ & $24(28 \%)$ & $16(23 \%)$ & \\
\hline Completed elementary $[n(\%)]$ & $58(37 \%)$ & $26(31 \%)$ & $32(46 \%)$ & \\
\hline Reached high school $[n(\%)]$ & $37(24 \%)$ & $23(27 \%)$ & $14(20 \%)$ & \\
\hline Reached college $[n(\%)]$ & $20(13 \%)$ & $12(14 \%)$ & $8(11 \%)$ & \\
\hline Diabetes duration in years [mean (SD)] & $4.39(5.31)$ & $3.98(5.38)$ & $4.90(5.21)$ & 0.28 \\
\hline
\end{tabular}

DSME = diabetes self-management education.

Primary Health Care Research \& Development 2017; 18: 35-49 
Table 2 Comparison of anthropometric measures between diabetes self-management education (DSME) group and standard care group at baseline, third and sixth month

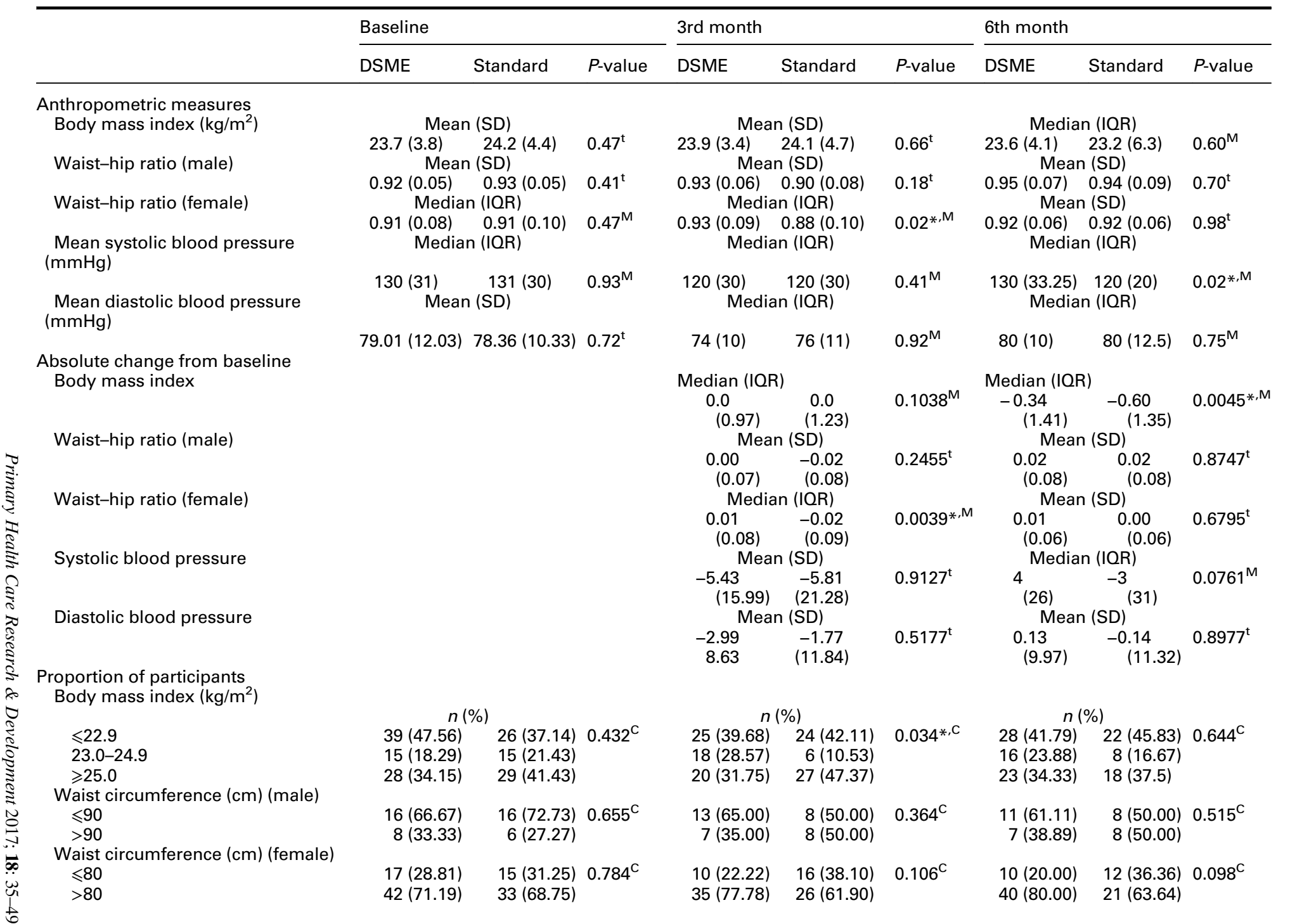




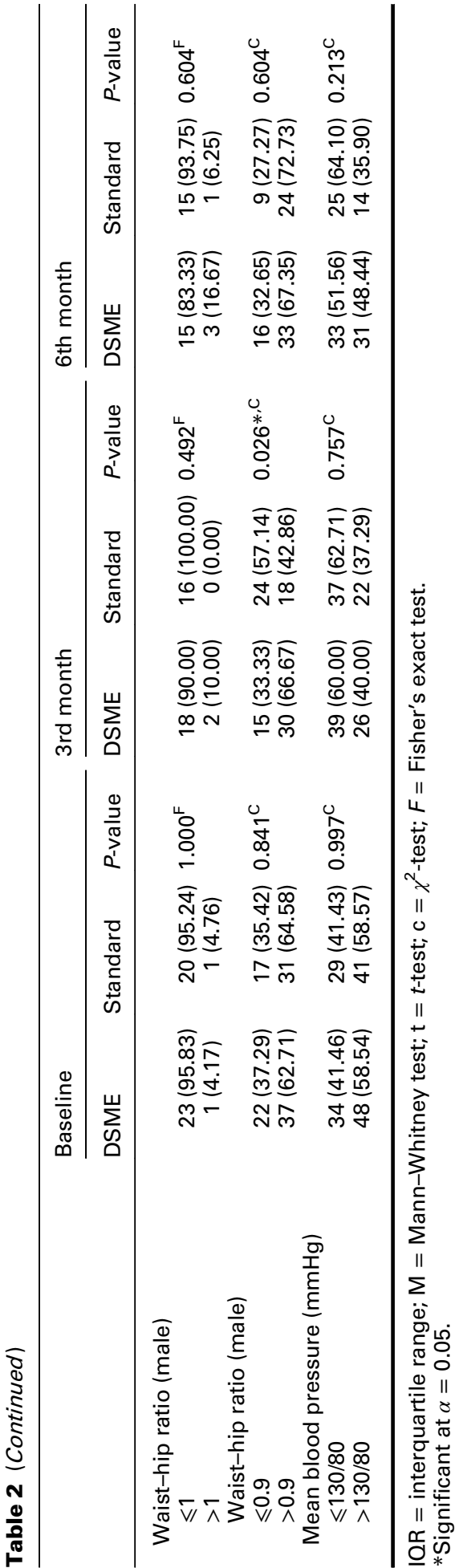

Primary Health Care Research \& Development 2017; 18: 35-49
$\left(\mathrm{BMI} \geqslant 25.0 \mathrm{~kg} / \mathrm{m}^{2}\right)$ were similar for both groups at baseline. At third month, however, there were more obese participants in the standard care group compared with the DSME group (47.37 versus $31.75 \%, P=0.034)$. This difference did not persist at the sixth month when the proportions of participants with the various BMI categories were similar in both groups.

The proportions of participants having the recommended waist circumference of $\leqslant 90 \mathrm{~cm}$ for Asian males and $\leqslant 80 \mathrm{~cm}$ for Asian females were equal for both groups at all time points.

The proportions of males having the recommended WHR of $\leqslant 1.0$ were similar for both groups at all time points. However, for females, the proportions of those having elevated WHR $(>0.9)$ were similar at baseline, but were higher in the DSME group by the third month (66.67 versus $42.86 \%, P=0.026$ ), but were again similar by the sixth month.

The proportion of participants achieving the recommended blood pressure of $\leqslant 130 / 80 \mathrm{mmHg}$ was similar for both groups at all time points.

There was no difference in the change in BMI at the third month from baseline in the two groups. However, there was a smaller reduction in BMI over a six-month period in the DSME group compared with the standard care group $(-0.34$ versus $\left.-0.60 \mathrm{~kg} / \mathrm{m}^{2}, P=0.0045\right)$.

There was a significant difference in the change in the WHR, only among females, at the third month from baseline. For the DSME group, there was an increase of 0.01 , whereas in the standard care group, there was a decrease of 0.02 $(P=0.0039)$. This difference in the change in WHR, however, was not seen when we compared the WHR at the sixth month with the WHR at baseline.

There were no differences in the change in systolic and diastolic blood pressure measurements over a three-month period and over a six-month period between the two groups.

\section{Biochemical measures (see Table 3)}

Median A1C levels were similar between the DSME and standard care groups at baseline. However, the median A1C level of the DSME group is lower than that of the standard care group on the third month (6.75 versus $8.5 \%, P=0.03)$ and on the sixth month (6.45 versus $7.6 \%$, 
Table 3 Comparison of biochemical measures between diabetes self-management education (DSME) group and standard care group at baseline, third and sixth month

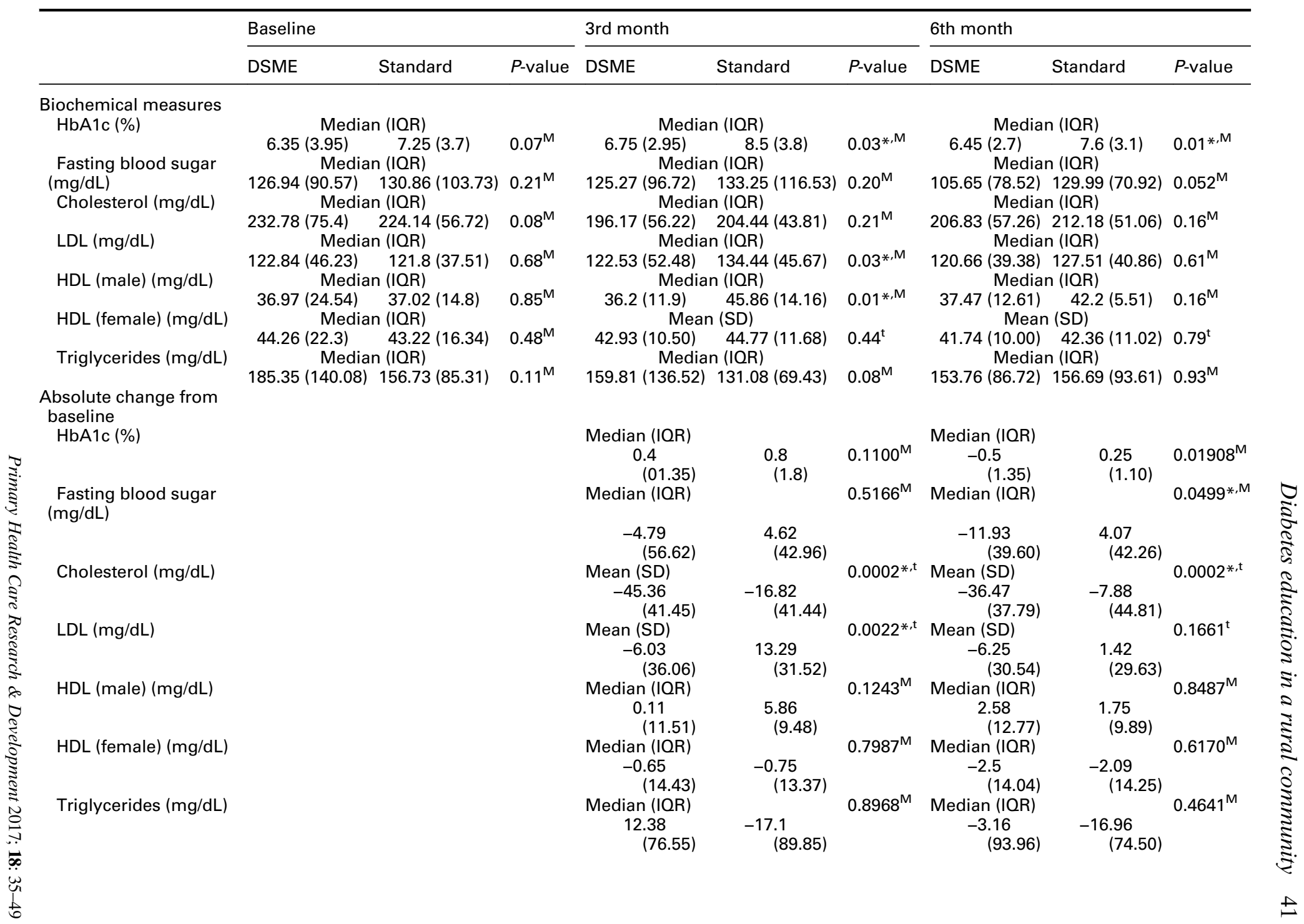




$$
\begin{aligned}
& \text { Total ch } \\
& (\mathrm{mg} / \mathrm{dL})
\end{aligned}
$$$$
>200
$$$$
\mathrm{LDL}(\mathrm{mg} / \mathrm{dL})
$$$$
\leqslant 100
$$$$
>100
$$

HDL (male) (mg/dL)

$\geqslant 40$

$<40$

$\mathrm{HDL}$ (female) $(\mathrm{mg} / \mathrm{dL})$
$\geqslant 50$
$<50$

Triglycerides $(\mathrm{mg} / \mathrm{dL})$

$\leqslant 150$

$>150$

$n(\%)$

$n(\%)$

$n(\%)$

\begin{tabular}{|c|c|c|c|c|c|c|c|c|}
\hline $\begin{array}{l}44(52.38) \\
40(47.62)\end{array}$ & $\begin{array}{l}30(42.86) \\
40(57.14)\end{array}$ & $0.2390^{c}$ & $\begin{array}{l}33(55.00) \\
27(45.00)\end{array}$ & $\begin{array}{l}19(35.19) \\
35(64.81)\end{array}$ & $0.0340^{*, c}$ & $\begin{array}{l}43(59.72) \\
29(40.28)\end{array}$ & $\begin{array}{l}20(38.46) \\
32(61.54)\end{array}$ & $0.0190^{*, c}$ \\
\hline $\begin{array}{l}44(51.76) \\
41(48.24)\end{array}$ & $\begin{array}{l}34(48.57) \\
36(51.43)\end{array}$ & $0.6920^{c}$ & $\begin{array}{l}34(53.97) \\
29(46.03)\end{array}$ & $\begin{array}{l}25(43.10) \\
33(56.90)\end{array}$ & $0.2320^{c}$ & $\begin{array}{l}44(61.97) \\
27(38.03)\end{array}$ & $\begin{array}{l}26(50.00) \\
26(50.00)\end{array}$ & $0.1850^{c}$ \\
\hline $\begin{array}{l}20(23.53) \\
65(76.47)\end{array}$ & $\begin{array}{l}21(30.00) \\
49(70.00)\end{array}$ & $0.3630^{c}$ & $\begin{array}{l}34(53.97) \\
29(46.03)\end{array}$ & $\begin{array}{l}28(48.28) \\
30(51.72)\end{array}$ & $0.5310^{c}$ & $\begin{array}{l}29(40.85) \\
42(59.15)\end{array}$ & $\begin{array}{l}17(32.69) \\
35(67.31)\end{array}$ & $0.3560^{c}$ \\
\hline $\begin{array}{l}18(21.18) \\
67(78.82)\end{array}$ & $\begin{array}{l}14(20.00) \\
56(80.00)\end{array}$ & $0.8570^{c}$ & $\begin{array}{l}17(26.98) \\
46(73.02)\end{array}$ & $\begin{array}{r}9(15.52) \\
49(84.48)\end{array}$ & $0.1250^{c}$ & $\begin{array}{l}17(23.94) \\
54(76.06)\end{array}$ & $\begin{array}{l}11(21.15) \\
41(78.85)\end{array}$ & $0.7150^{c}$ \\
\hline $\begin{array}{l}11(44.00) \\
14(56.00)\end{array}$ & $\begin{array}{r}8(36.36) \\
14(63.64)\end{array}$ & $0.5950^{c}$ & $\begin{array}{r}6(31.58) \\
13(68.42)\end{array}$ & $\begin{array}{r}12(70.59) \\
5(29.41)\end{array}$ & $0.0190^{*, \mathrm{c}}$ & $\begin{array}{r}9(42.86) \\
12(57.14)\end{array}$ & $\begin{array}{l}9(52.94) \\
8(47.06)\end{array}$ & $0.5360^{c}$ \\
\hline $\begin{array}{l}21(35.00) \\
39(65.00)\end{array}$ & $\begin{array}{l}16(33.33) \\
32(66.67)\end{array}$ & $0.8560^{c}$ & $\begin{array}{r}8(18.18) \\
36(81.82)\end{array}$ & $\begin{array}{l}14(34.15) \\
27(65.85)\end{array}$ & $0.0930^{c}$ & $\begin{array}{l}10(20.00) \\
40(80.00)\end{array}$ & $\begin{array}{r}6(17.14) \\
29(82.86)\end{array}$ & $0.7400^{c}$ \\
\hline $\begin{array}{l}32(37.65) \\
53(62.35)\end{array}$ & $\begin{array}{l}31(44.29) \\
39(55.71)\end{array}$ & $0.4020^{c}$ & $\begin{array}{l}29(46.03) \\
34(53.97)\end{array}$ & $\begin{array}{l}35(60.34) \\
23(39.66)\end{array}$ & $0.1150^{c}$ & $\begin{array}{l}32(45.07) \\
39(54.93)\end{array}$ & $\begin{array}{l}24(46.15) \\
28(53.85)\end{array}$ & $0.9050^{c}$ \\
\hline
\end{tabular}

$\mathrm{HbA} 1 \mathrm{c}=$ hemoglonin $\mathrm{A} 1 \mathrm{c} ; \mathrm{HDL}=$ high density lipoprotein; $\mathrm{IQR}=$ interquartile range; $\mathrm{LDL}=$ low density lipoprotein; $\mathrm{M}=\mathrm{Mann}-\mathrm{Whitney}$ test; $\mathrm{t}=\mathrm{t}$-test; $\mathrm{c}=\chi^{2}$-test.

${ }^{*}$ Significant at $\alpha=0.05$. 
Table 4 Comparison of behavioral measures between the diabetes self-management education (DSME) and standard care groups at baseline, third and sixth month

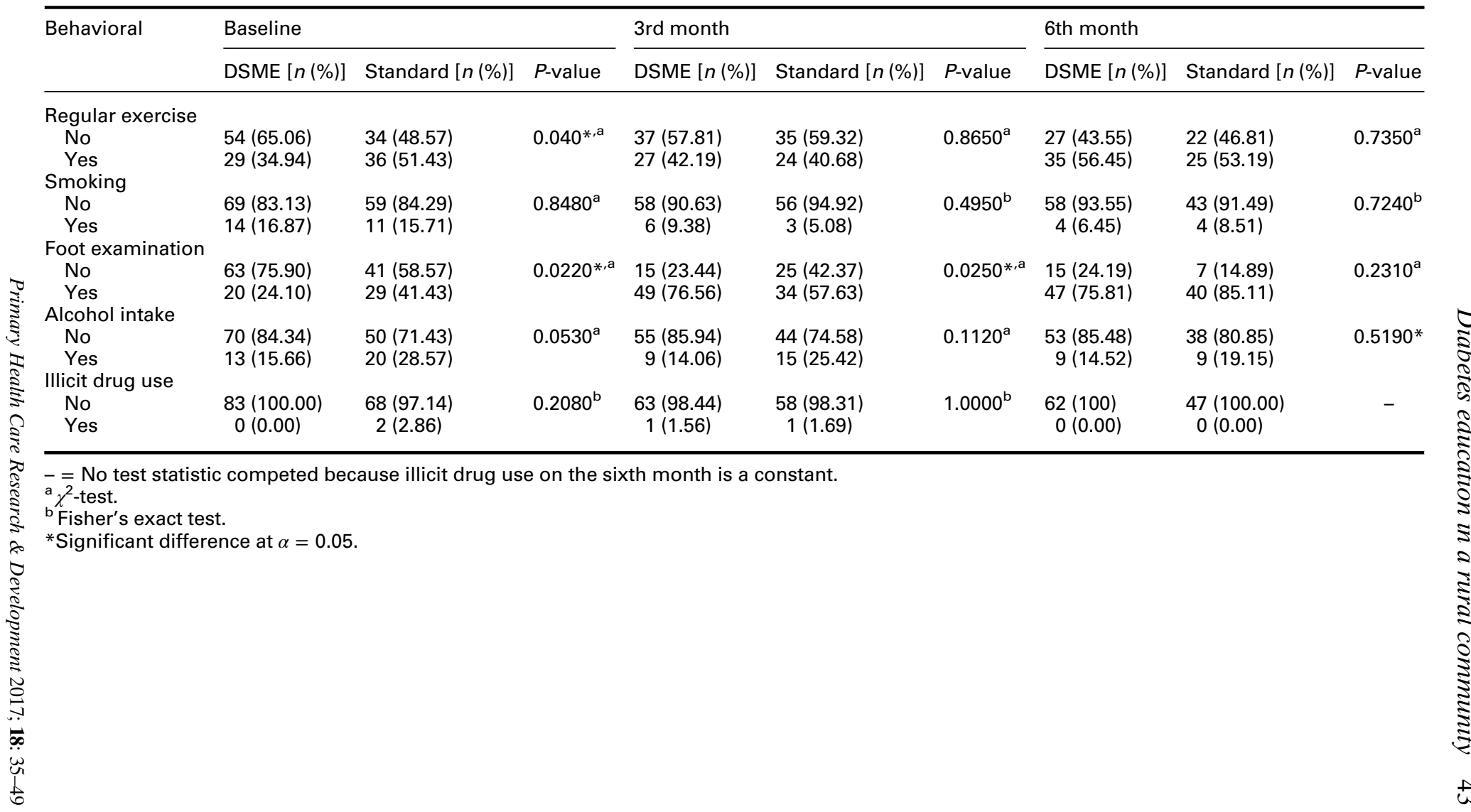


$P=0.01)$. In terms of absolute change in A1C, there was no difference between the two groups on the third month. But on the sixth month, the two groups were found to have a significant difference $(P=0.019)$. Specifically, the DSME group was found to have a median $\mathrm{A} 1 \mathrm{C}$ reduction of $0.5 \%$, whereas the standard care group had a median increase of $0.25 \%$ by the sixth month.

FBG levels were likewise similar for the DSME and standard care group at all time points. In terms of absolute change in FBG, there was no difference between the two groups on the third month. But on the sixth month, the two groups were again found to have a significant difference $(P=0.0499)$. Specifically, the DSME group was found to have a median FBG reduction of $11.93 \mathrm{mg} / \mathrm{dL}$, whereas the standard care group had a median increase of $4.07 \mathrm{mg} / \mathrm{dL}$ on the sixth month as compared with baseline.

Total cholesterol levels were also similar for the DSME and standard care group at all time points. However, there was a greater decrease in total cholesterol by the third month in the DSME group compared with the standard care group $(-45.4$ versus $-16.8 \mathrm{mg} / \mathrm{dL}, P=0.0002$ ), as well as on the sixth month $(-36.47$ versus $-7.88, P=0.0002)$.

LDL levels were similar between the DSME and standard care groups at baseline and on the sixth month. However, the median LDL levels of the DSME group are lower than the standard care group on the third month (122.53 versus $134.44 \mathrm{mg} / \mathrm{dL}$, $P=0.03)$. In terms of absolute change in LDL, there was no difference between the two groups on the sixth month. But on the third month, the two groups were found to have a significant difference $(P=0.0022)$. Specifically, the DSME group was found to have a mean LDL reduction of $6.03 \mathrm{mg} / \mathrm{dL}$, whereas the standard care group had a mean LDL increase of $13.29 \mathrm{mg} / \mathrm{dL}$ by the third month.

Mean HDL cholesterol levels in males were similar at baseline. However, at the third month, there was a lower mean HDL level among males in the DSME group compared with the standard care group ( 36.20 versus $45.86 \mathrm{mg} / \mathrm{dL}, P=0.01$ ). By the sixth month, the mean HDL levels in males were again similar for both groups.

HDL levels for females and triglycerides were similar for both groups at baseline, third month and sixth month.

The proportion of participants achieving the recommended A1C level of $\leqslant 7.0 \%$ was similar for

Primary Health Care Research \& Development 2017; 18: 35-49 both groups at baseline. However, by the third month, there were now more participants in the DSME group who had A1C $\leqslant 7.0 \%$ compared with the standard care group (55.00 versus $35.19 \%$, $P=0.0340)$. This difference was still apparent by the sixth month (59.72 versus $38.46 \%$, $P=0.0190)$.

The proportion of participants achieving the recommended values for FBG, total cholesterol, LDL, triglycerides, and HDL (for females) was similar for both groups across all time points.

For the recommended HDL level for males of $\geqslant 40 \mathrm{mg} / \mathrm{dL}$, the proportion achieving this was similar at baseline for both groups. However, there were fewer participants in the DSME group achieving this by the third month compared with the standard care group (31.58 versus $70.59 \%$, $P=0.0190)$. There were again similar proportions achieving the recommended HDL level for males by the sixth month.

\section{Health behavior measures (see Table 4)}

At baseline, the performance of regular exercise was being done by a fewer number of participants in the DSME group compared with the standard care group (34.94 versus $51.43 \%, P=0.040$ ). However, by the third and sixth months, the proportion of participants performing regular exercise were already comparable.

Moreover, at baseline, the performance of foot examination was initially done by a fewer number of participants in the DSME group compared with the standard care group (24.10 versus $41.43 \%$, $P=0.0220)$. However, the trend was reversed by the third month when there were now more participants in the DSME group performing foot examination (76.56 versus $57.63 \%, P=0.0250$ ). By the sixth month, there was no more difference in the proportion of participants in the two groups who perform foot examination (75.81 versus $85.11 \%, P=0.2310)$. Note that in both groups, the number of participants performing foot examination increased by the sixth month compared with baseline (from 24.10 to $75.81 \%$ in the DSME group, and from 41.43 to $85.11 \%$ in the standard care group).

The proportion of participants who smoke cigarettes, consume alcohol and use illicit drugs were similar for both groups at all time points. 


\section{Medication use (see Table 5)}

The proportions of participants taking medications for diabetes were similar for both groups at all time points, except for metformin and insulin.

There was no participant in the DSME group who was receiving insulin at baseline, but there were $5.71 \%$ in the standard care group who were $(P=0.0400)$. However, this difference was not anymore seen at the third and sixth months as there were no more participants using insulin in both groups at those time points.

There was a higher proportion of participants in the DSME group taking metformin at the third month compared with the standard group (41.54 versus $22.03 \%, P=0.0333)$. This difference, however, was not anymore seen at the sixth month.

The proportion of participants taking the various medications for dyslipidemia and hypertension was similar for both groups at all time points.

\section{Discussion}

From these results, the only consistent outcome that was different in the DSME group and the standard care group was the A1C (Table 6). The DSME group had lower median A1C levels at the third and sixth months, a decrease in A1C from baseline at the sixth month (versus an increase in the standard care group), and had more participants achieving the recommended level of $\mathrm{A} 1 \mathrm{C} \leqslant 7.0 \%$ at the third and sixth months.

There were some significant differences in terms of BMI, WHR, systolic blood pressure, FBG, total cholesterol, and HDL, but these were neither consistently demonstrated at both the third and sixth month follow-up nor were they consistently demonstrated when it comes to the differences in means/medians, change from baseline, and proportion of those achieving the recommended values (Table 6).

The change in $\mathrm{A} 1 \mathrm{C}$ can be argued to be due to the higher use of metformin in the DSME group at the third month. However, the differences in A1C persisted until the sixth month when by that time, there was no more difference in the use of metformin by the two groups. Also, no medication was provided by the investigators. The increase in the proportion of those taking metformin is not due to the investigators' provision of medications, but could be as a result of increased compliance as the education modules emphasized the need to regularly take prescribed medications.

The consistent finding of better glycemic control in the DSME group compared with the standard care group at three and six months demonstrated how education can have an impact on this important parameter. This finding is consistent with other DSME programs done in resource-limited areas. It has been shown that hemoglonin A1c (HbA1c) went down by as much as 1.4 to $1.7 \%$ in DSME programs done in an impoverished rural community at the Mexico-Texas border (Brown and Hanis, 2014). A DSME program done in an underserved community of Hispanics and blacks in Chicago gave a mean $0.5 \%$ lowering in HbA1c (Hughes et al., 2016). An underserved, predominantly Hispanic community in the United States has benefited from a DSME program as shown by a reduction in HbA1c from 8.3 to $7.4 \%$ (Kane et al., 2016). A change from 10.1 to $8.9 \%$ in $\mathrm{HbA1c}$ in a DSME program given to the indigenous Tz'utujil Maya of Guatemala has been demonstrated by Micikas (Micikas et al., 2015). A DSME program delivered by nurses led to a $0.14 \%$ reduction in HbA1c in Thailand (Jaipakdee et al., 2015). It has also been shown in Sri Lanka that a greater number of patients who received DSME were able to achieve an HbA1c $<6.5 \%$ compared with those who did not (28 versus $8 \%$ ) (Jayasuriya et al., 2015). Our study is distinct compared with the others as we made use of peer educators as implementers of the DSME, whereas other studies involved community health workers and nurses.

For the health behavior outcomes, there was an increase in performance of foot examination in both the DSME and standard care groups, but there was a much greater increase in the proportion of those performing this simple habit in the DSME group. Improvements in foot care have also been shown in other DSME programs implemented in rural African-American communities in Texas and Virginia (Williams et al., 2014; Pena-Purcell et al., 2015). It is enlivening to find out that education can influence people to perform this simple task which can potentially reduce foot problems.

This study utilized volunteer peer educators with diabetes who were trained to cover eight modules on diabetes and its care. The lack of

Primary Health Care Research \& Development 2017; 18: 35-49 
Table 5 Comparison of medication use between the diabetes self-management education (DSME) and standard care groups at baseline, third and sixth month

\begin{tabular}{|c|c|c|c|c|c|c|c|c|c|}
\hline \multirow[t]{2}{*}{ Medication use } & \multicolumn{3}{|l|}{ Baseline } & \multicolumn{3}{|l|}{ 3rd month } & \multicolumn{3}{|l|}{ 6th month } \\
\hline & $\begin{array}{l}\text { DSME }[n / N \\
(\%)]\end{array}$ & $\begin{array}{l}\text { Standard }[n / N \\
(\%)]\end{array}$ & $P$-value & $\begin{array}{l}\text { DSME }[n / N \\
(\%)]\end{array}$ & $\begin{array}{l}\text { Standard }[n / N \\
(\%)]\end{array}$ & $P$-value & $\begin{array}{l}\text { DSME }[n / N \\
(\%)]\end{array}$ & $\begin{array}{l}\text { Standard }[n / N \\
(\%)]\end{array}$ & $P$-value \\
\hline \multicolumn{10}{|l|}{ For diabetes } \\
\hline Sulfonylurea & 26/85 (30.59\%) & $25 / 70(24.29 \%)$ & $0.6240^{a}$ & $19 / 65(29.23 \%)$ & $19 / 59(32.20 \%)$ & $0.8701^{a}$ & $26 / 72(36.11 \%)$ & $24 / 52(46.15 \%)$ & $0.3475^{a}$ \\
\hline Metformin & $34 / 85(40.00 \%)$ & $28 / 70(40.00)$ & $1.0000^{\mathrm{a}}$ & $27 / 65(41.54 \%)$ & $13 / 59(22.03 \%)$ & $0.0333^{*, a}$ & $20 / 72(27.78 \%)$ & $13 / 52(25.00 \%)$ & $0.8891^{\mathrm{a}}$ \\
\hline $\begin{array}{l}\text { Alpha glucosidase } \\
\text { inhibitor }\end{array}$ & $0 / 85(0.00 \%)$ & $3 / 70(4.29 \%)$ & $0.0540^{b}$ & $1 / 65(1.54 \%)$ & $1 / 59(1.69 \%)$ & $1.0000^{\mathrm{b}}$ & $1 / 72(1.39 \%)$ & $1 / 52(1.92 \%)$ & $1.0000^{b}$ \\
\hline Thiazolidinedione & $1 / 85(1.18 \%)$ & $3 / 70(4.29 \%)$ & $0.2240^{\mathrm{b}}$ & $1 / 65(1.54 \%)$ & $2 / 59(3.39 \%)$ & $0.6043^{b}$ & $1 / 72(1.39 \%)$ & $0 / 52(0.00 \%)$ & $1.0000^{\mathrm{b}}$ \\
\hline $\begin{array}{l}\text { Dipeptidy peptidase-4 } \\
\text { inhibitor }\end{array}$ & $0 / 85(0.00 \%)$ & $1 / 70(1.43 \%)$ & $0.2690^{\mathrm{b}}$ & 1/65 (1.54\%) & $0 / 59(0.00 \%)$ & $1.0000^{b}$ & $1 / 72(1.39 \%)$ & $0 / 52(0.00 \%)$ & $1.0000^{\mathrm{b}}$ \\
\hline $\begin{array}{l}\text { Any oral antidiabetic } \\
\text { agent }\end{array}$ & 49/85 (57.65\%) & $42 / 70(60.00 \%)$ & $0.8948^{a}$ & $37 / 65(56.92 \%)$ & $26 / 59(44.07 \%)$ & $0.2112^{\mathrm{a}}$ & $25 / 72(34.72 \%)$ & $20 / 52(38.46 \%)$ & $0.8118^{a}$ \\
\hline $\begin{array}{l}\text { Insulin } \\
\text { For dyslipidemia }\end{array}$ & $0 / 85(0.00 \%)$ & 4/70 (5.71\%) & $0.0400^{*, b}$ & $0 / 65(0.00 \%)$ & $0 / 59(0.00 \%)$ & - & $0 / 72(0.00 \%)$ & $0 / 52(0.00 \%)$ & - \\
\hline Statins & 6/85 (7.06\%) & $3 / 70(4.29 \%)$ & $0.5140^{b}$ & 7/65 (10.77\%) & 6/59 (10.17\%) & $1.0000^{b}$ & $0 / 72(0.00 \%)$ & $0 / 52(0.00 \%)$ & - \\
\hline Fibrate & 0/85 (0.00\%) & $0 / 70(0.00 \%)$ & - & $1 / 65(1.18 \%)$ & $0 / 59(0.00 \%)$ & $1.0000^{\mathrm{b}}$ & $1 / 72(1.39 \%)$ & $0 / 52(0.00 \%)$ & $1.0000^{b}$ \\
\hline \multicolumn{10}{|l|}{ For hypertension } \\
\hline $\begin{array}{l}\text { Angiotensin converting } \\
\text { enzyme inhibitor }\end{array}$ & 3/85 (3.53\%) & $2 / 70(2.86 \%)$ & $1.0000^{b}$ & $5 / 65(7.69 \%)$ & $0 / 59(0.00 \%)$ & $0.0589^{b}$ & $5 / 72(6.94 \%)$ & $1 / 52(1.92 \%)$ & $0.3993^{b}$ \\
\hline $\begin{array}{l}\text { Angiotensin receptor } \\
\text { blocker }\end{array}$ & $5 / 85(5.86 \%)$ & 4/70 (5.71\%) & $1.0000^{\mathrm{b}}$ & $3 / 65(4.62 \%)$ & 2/59 (3.39\%) & $1.0000^{b}$ & 4/72 (5.55\%) & $1 / 52(1.92 \%)$ & $0.3979^{b}$ \\
\hline $\begin{array}{l}\text { Calcium channel } \\
\text { blocker }\end{array}$ & $3 / 85(3.53 \%)$ & $2 / 70(2.86 \%)$ & $1.0000^{\mathrm{b}}$ & $5 / 65(7.69 \%)$ & $4 / 59(6.78 \%)$ & $1.0000^{\mathrm{b}}$ & 4/72 (5.55\%) & $2 / 52(3.85 \%)$ & $1.0000^{\mathrm{b}}$ \\
\hline Beta blocker & 4/85 (4.71\%) & $2 / 70(2.86 \%)$ & $0.6900^{b}$ & $4 / 65(6.15 \%)$ & $1 / 59(1.69 \%)$ & $0.3677^{b}$ & $3 / 72(4.17 \%)$ & $1 / 52(1.92 \%)$ & $0.6387^{b}$ \\
\hline
\end{tabular}

a $\chi^{2}$-test.

b Fisher's exact test.

*Significant difference at $\alpha=0.05$. 
Table 6 Summary of significant differences between diabetes self-management education (DSME) and standard care groups

\begin{tabular}{|c|c|c|c|c|}
\hline \multirow[t]{2}{*}{ Outcome measures } & \multirow[t]{2}{*}{ Follow-up } & \multicolumn{3}{|c|}{ Differences between DSME and standard care groups } \\
\hline & & Mean or median & Change from baseline & $\begin{array}{l}\text { Proportion of participants } \\
\text { with recommended level }\end{array}$ \\
\hline \multicolumn{5}{|l|}{ Anthropometric } \\
\hline \multirow[t]{2}{*}{ Body mass index } & 3rd month & NS & NS & DSME better \\
\hline & 6th month & NS & Standard care better & NS \\
\hline \multirow[t]{2}{*}{ Waist circumference (males) } & 3rd month & NS & NS & NS \\
\hline & 6th month & NS & NS & NS \\
\hline \multirow[t]{2}{*}{ Waist circumference (females) } & 3rd month & NS & NS & NS \\
\hline & 6th month & NS & NS & NS \\
\hline \multirow[t]{2}{*}{ Waist-hip ratio (males) } & 3rd month & NS & NS & NS \\
\hline & 6th month & NS & NS & NS \\
\hline Waist-hip ratio (females) & $\begin{array}{l}\text { 3rd month } \\
6 \text { th month }\end{array}$ & $\begin{array}{l}\text { Standard care better } \\
\text { NS }\end{array}$ & $\begin{array}{l}\text { Standard care better } \\
\text { NS }\end{array}$ & $\begin{array}{l}\text { Standard care better } \\
\text { NS }\end{array}$ \\
\hline \multirow[t]{2}{*}{ Systolic blood pressure } & 3rd month & NS & NS & NS \\
\hline & 6th month & Standard care better & NS & NS \\
\hline \multirow{2}{*}{ Diastolic blood pressure } & 3rd month & NS & NS & NS \\
\hline & 6th month & NS & NS & NS \\
\hline \multicolumn{5}{|l|}{ Biochemical } \\
\hline \multirow[t]{2}{*}{ HbA1c } & 3rd month & DSME better & NS & DSME better \\
\hline & 6th month & DSME better & DSME better & DSME better \\
\hline \multirow[t]{2}{*}{ Fasting blood sugar } & 3rd month & NS & NS & NS \\
\hline & 6th month & NS & DSME better & NS \\
\hline \multirow[t]{2}{*}{ Total cholesterol } & 3rd month & NS & DSME better & NS \\
\hline & 6th month & NS & DSME better & NS \\
\hline \multirow[t]{2}{*}{ LDL } & 3rd month & DSME better & DSME better & NS \\
\hline & 6th month & NS & NS & NS \\
\hline \multirow[t]{2}{*}{ HDL (males) } & 3rd month & Standard care better & NS & Standard care better \\
\hline & 6th month & NS & NS & NS \\
\hline \multirow[t]{2}{*}{ HDL (females) } & 3rd month & NS & NS & NS \\
\hline & 6th month & NS & NS & NS \\
\hline \multirow[t]{2}{*}{ Triglycerides } & 3rd month & NS & NS & NS \\
\hline & 6th month & NS & NS & NS \\
\hline
\end{tabular}

$\mathrm{HbA1c}=$ hemoglonin $\mathrm{A} 1 \mathrm{c} ; \mathrm{HDL}=$ high density lipoprotein; $\mathrm{LDL}=$ low density lipoprotein; NS = not significant.

health professionals then does not become a limitation for diabetes education in these areas. The team of endocrinologists did not find difficulty in discussing the module content to the peer educators. The same is true when the peer educators were teaching the study participants, even if majority of the residents in this rural community only completed elementary education. The grasp by the peer educators of the content and manner of delivery of the modules was verified by return demonstration.

Having peer educators ensures the continuity or sustainability of this education program even after this study has ended. Our trained peer educators can continue to disseminate what they have learned to their village mates whether in a formal manner or through informal conversations, even after our team of endocrinologists are not anymore physically present in this rural community.

There were several realities in the community setting that had to be faced as the investigators embarked on this program. They seemed to be barriers at the beginning, but the team has learned to work around these as we implemented the program. These were conflicts in schedule between our project activities and other local social activities (specifically the national and local elections), participants' inability to follow-up because of domestic concerns, access to the health centers, and difficulty in disseminating information in a community where there are limited means of communication. These were

Primary Health Care Research \& Development 2017; 18: 35-49 
circumvented by more frequent trips to the villages and even visits to the participants' homes, and understanding that their participation in this program is just one of the many social and domestic concerns that require their attention.

A limitation of this study is that the number of participants in the standard care group who followed up at the end of the study (52 out of the original 70 participants, $74 \%$ ) is less than the computed sample size of 65 per group. This lower follow-up rate was a reality we had to accept in the rural community as our patients had many other social and domestic concerns to attend to. The follow-up rate was better in the DSME group ( 72 out of $85,85 \%$ ) probably because of the more frequent and deeper level of interactions they had with the investigators during the teaching sessions which encouraged them to continue with the study.

An important implication of this study is that this approach can be adapted in other similar resource-limited rural communities.

\section{Conclusion}

This pilot study in a rural agricultural community in the Philippines has shown that DSME delivered by volunteer peer educators is an effective tool in improving $\mathrm{A} 1 \mathrm{C}$ and promoting foot examination.

\section{Acknowledgments}

Acknowledgements go to the Sentro ng Wikang Filipino of the University of the Philippines Manila for translating the IDF modules into Filipino; to the Municipal Government of San Juan headed by Mayor Danilo S. Mindanao (2007-10) and Mayor Rodolfo H. Manalo (2010-present); the Municipal Health Office headed by the Nestor Alidio (MD), with the midwives and village health workers; the chairmen of the participating villages; our community organizers Melani Sagun, Zandro Pinca (RN), and Manilyn Prudente (RM); our statisticians Aristotle Magallanes and Madonna Valenzuela, our laboratory staff Aurora Laurel, Rhoda Montemayor (RMT), Lenore Grefal (RMT), and Hazel Jayohoy (RMT); and the community medicine interns of the Philippine General Hospital.

Primary Health Care Research \& Development 2017; 18: 35-49

\section{Financial Support}

This project is supported by a BRIDGES (Bringing Research in Diabetes to Global Environments and Systems) grant from the IDF. BRIDGES, an IDF project, is supported by an educational grant from Eli Lilly and Company.

\section{Conflicts of Interest}

None.

\section{Ethical Standards}

The authors assert that all procedures contributing to this work comply with the ethical standards of the relevant national and institutional guidelines on human experimentation of the Research Implementation and Development Office of the University of the Philippines College of Medicine and with the Helsinki Declaration of 1975 , as revised in 2008 .

\section{References}

Brown, S. and Hanis, C.L. 2014: Lessons learned from 20 years of diabetes self-management research with Mexican Americans in Starr County, Texas. Diabetes Educator 40, 476-87.

Fraser, R., Skinner, A. and Mueller, K.J. 2006. RUPRI center for rural health policy analysis: elements of successful rural diabetes management programs. Omaha, NE: University of Nebraska Medical Center.

Hughes, M.M., Yang, E., Ramanathan, D. and Benjamins, M.R. 2016: Community-based diabetes community health worker intervention in an underserved Chicago population. Journal of Community Health, doi:10.1007/s10900-016-0212-8.

Jaipakdee, J., Jiamjarasrangsi, W., Lohsoonthorn, V. and Lertmaharit, S. 2015: Effectiveness of a self-management support program for Thais with type 2 diabetes: Evaluation according to the RE-AIM framework. Nursing and Health Sciences 17, 362-69.

Jayasuriya, R., Pinidiyapathirage, M.J., Jayawardena, R., Kasturiratne, A., de Zoysa, P., Godamunne, P., Gamage, S. and Wickremasinghe, A.R. 2015: Translational research for diabetes self-management in Sri Lanka: a randomized controlled trial. Primary Care Diabetes 9, 338-45.

Kane, E.P., Collinsworth, A.W., Schmidt, K.L., Brown, R.M., Snead, C.A., Barnes, S.A., Fleming, N.S. and Walton, J.W. 2016: Improving diabetes care and outcomes with community health workers. Family Practice, doi:10.1093/fampra/ cmw055. 
Kronsbein, P., Muhlhauser, I., Venhaus, A., Jorgens, V., Scholz, V. and Berger, M. 1988: Evaluation of a structured treatment and teaching programme on non-insulindependent diabetes. Lancet 17, 1407-410.

Mensing, C., Boucher, J., Cypress, M., Weinger, K., Mulcahy, K., Barta, P., Hosey, G., Kopher, W., Lasichak, A., Lamb, B., Mangan, M., Norman, J., Tanja, J., Yauk, L., Wisdom, K. and Adams, C. 2000: National standards for diabetes selfmanagement education. Diabetes Care 23, 682-89.

Micikas, M., Foster, J., Weis, A., Lopez-Salm, A., Lungelow, D., Mendez, P. and Micikas, A. 2015: A community health worker intervention for diabetes self-management among the Tz'utujil Maya of Guatemala. Health Promotion and Practice $16,601-8$.

Norris, S., Engelgau, M. and Venkat Narayan, K.M. 2001: Effectiveness of self-management training in type 2 diabetes: a systematic review of randomized controlled trials. Diabetes Care 24, 583-85.

Norris, S., Lau, J., Smith, S.J., Schmid, C. and Engelgau, M. 2002: Self-management education for adults with type 2 diabetes: a meta-analysis of the effect on glycemic control. Diabetes Care 25, 1159-171.

Pena-Purcell, N.C., Jiang, L., Ory, M.G. and Hollingsworth, R. 2015: Translating an evidence-based diabetes education approach into rural African-American communities: The 'Wisdom, Power, Control' Program. Diabetes Spectrum 28, 106-15.
Plescia, M. and Groblewski, M. 2004: A community-oriented primary care demonstration project: refining interventions for cardiovascular disease and diabetes. Annals of Family Medicine 2, 103-9.

Salman, G.F. 2005: Continuous quality improvement in rural health clinics. General Internal Medicine 20, 862-65.

Sandoval, M.A.S., Paz-Pacheco, E., Ardena, G.J.R.A., Lantion-Ang, F.L., Paterno, E., Juban, N. and Jimeno, C. 2016: Socio-economic realities in a rural Filipino community lead volunteer bias in a survey of diabetes, prediabetes and metabolic syndrome. Social Medicine 10, 30-35.

Sy, R.G., Morales, D.D., Dans, A.L., Paz-Pacheco, E., Punzalan, F.E., Abelardo, N.S. and Duante, C.A. 2012: Prevalence of atherosclerosis-related risk factors and diseases in the Philippines. Journal of Epidemiology 22, 440-47.

Task Force on Community Preventive Services 2002: Recommendations for healthcare system and selfmanagement education interventions to reduce morbidity and mortality from diabetes. American Journal of Preventive Medicine 22 (4S), 10-14.

Williams, I.C., Utz, S.W., Hinton, I., Yan, G., Jones, R. and Reid, K. 2014: Enhancing diabetes self-care among rural African Americans with diabetes: results of a two-year culturally-tailored intervention. Diabetes Educator 40, 231-39. 